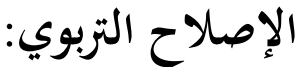

\section{العلاقة بين الرؤية الكونية والمنهجية المعرفية والأداء التربوي}

\section{* عبد الحميد أحمد أبوسليمان}

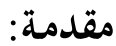

يحاول الكاتب في هذه الورقة توضيح العلاقة بين الرؤية الكونية والأداء التربوي، وكيف أنّ تصحيح المناهج المعرفية المتبعة في المناهج التربوية أمر ضروري لنجاح الإصلاح التربوي. ولتحقيق تلك الغاية حاول الكاتب متابعة السيرة التاريخيّة للفكر والثقافة الإسلامية ومناهجها المعرفية وما لحق بها من تغير وتطور يعكس الرؤية الكونية للأمة على مدى عصورها المتلاحقة، كما حاول معرفة أثر الظروف البيئة على التغيرات التي طرأت على هذه الرؤية، وبالتالي على مناهج المعرفة اللازمة للتجاوب مع هذه التطورات وأثر ذلك وانعكاسه على المناهج التربوية وتكوين العقلية والنفسية لأبناء الأمة في مختلف المراحل التي مرّ بها تاريخ

$$
\text { الأمة وحضارتا حتى اليوم. }
$$

و تأتي أهمية فهم هذه العلاقات لأننا نستطيع -من خلال فهم العلاقة بين الرؤية الكونية ومناهج

المعرفة ومناهج التربية- إعادة صياغة هذه الرؤية والمناهج كيما تستجيب لحاجات الأمة في واقعها المعاصر وظروفها وإمكاناةا، والتحديات التي تواجهها في هذا العصر، وبذلك يمكننا إعادة بناء عقلية أبنائنا ونفسياتم، وهما ركيزتان يقوم عليهما بناء المجتمع وأداء أفراده ومؤسساته، وترسمان طريق عطاء الأمة العمراني والحضاري. وأي إصلاح لا يقوم على فهم كلي شمولي لمذه العلاقات يكون إصلاحاً عشوائياً، لا يكتب له النجاح ولا يؤدي إلى تحقيق أهدافه الأساسية. 
كما تستعرض هذه الورقة طبيعة الرؤية الكونية التي جاء بها القرآن الكريم ومناهج الفكر التي انبثقت عنها، ثم ما طرأ على مجتمع الصدر الأول ومنطلقاته من تغيرات نجم عنها الصراع والفصام بين صفوة الفكر والعلماء، وصفوة السياسة والحكم والسلطان وكيف أثر ذلك على قدرة كل فريق على أداء دوره، وما نجم بالتالي عن ذلك من تشويه للرؤية الكونية الإسلامية التي أدت إلى تغيير في مناهج الفكر لكي تصبح -مع ما صحبها من فكر ومنطق نظري إغريقي- مناهج جزئية انعكست على ثقافة الأمة ومناهجها المعرفية لتصبح رؤية اجتماعية قاصرة فردية سلبية ذات مناهج معرفية جزئية نظرية استظهارية، تثبط الدوافع وتقضي على طاقات المبادرة والإبداع في الأمة، يأخذ بها الآخرون من يد الأمة قصب السبق، وينتهي آخرها إلى الضعف والعجز والهوان.

ولكي تتضح الرؤية فإنّ البحث يبدأ بالنظر في الواقع المسلم القائم وما يحتويه من السلبيات ووجوه

النقص والقصور، منقباً في ماضي الأمة عن الجذور والأحداث التي ساهمت في صياغة الواقع الراهن بهدف تحقيق فهم أعمق يعين على تكوين رؤية مستقبلية إصلاحية فعّالة، مبنية على فهم سليم لمواطن القوة والضعف في كيان الأمة، وعلى معرفة حقيقية بعوامل النمو والتغيير في ذلك الكيان.

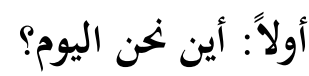

ليس موضع جدل أنّ الأمة الإسلامية في كليتها تعاني اليوم من أزمة وجود حضاري، وتقبع في هوة يتزايد مداها مع أمم العالم التي تملك زمام التقدم العلمي والتكنولوجي لتبلغ القيمة الكلية لإنتاج الأمة من المخيط إلى المحيط أقل من قيمة ربع إنتاج اليابان. واليابان مجموعة جزر بركانية صغيرة، ضئيلة الموارد الطبيعية، تغطي جلَّ سطحها الجبال، وتعصف بما الزلازل والبراكين، ويقطنها حوالي 130 مليون نسمة، وبهذا ندرك مدى ضعف أداء الأمة في بجال العلوم والعمران. فالأمة الإسلامية -رغم ثراء تاريخها وعظيم عطائها الحضاري على مدى عدد مديد من القرون التي انفردت فيها بالعطاء العلمي والحضاري- فإنها اليوم إنما تمثل رل مصدراً رخيص الثمن لإنتاج المواد الخام والعمالة اليدوية اللازمة لاستخراج المواد الخام وتركيب المنتجات والصناعات المستوردة. 
فإذا كانت صادرات العالم الإسلامي من المواد الخام تساوي الملايين القليلة من الدنانير، فإنّ وارداته من الصناعات التقنية العالية تساوي البلايين الكثيرة من الدنانير، والفرق بين منتجاتنا ومنتجات غيرنا هو فعل العقل الحضاري المبدع في مجالات العلم والصناعة والمعرفة التقنية العالية. إنّ تخلف أداء الأمة الإسلامية في مشارق الأرض ومغاربها لم يفقدها فقط موقع الصدارة وعز القدرة وريادة الطريق ولكنه هدد كياها السياسي والاقتصادي والثقافي، وأثخنها سياسياً واقتصادياً وثقافياً وعسكرياً، بحيث لم يعد لها من مقومات الأمم إلا الرسوم والشعارات المموهة الزائفة، التي لا تخفى إلا على أبناء شعوبها الغارقة في الجهل والتخلف والغفلة.

ومنذ أن زلزلت غيبوبة الأمة وسباها سنابك خيل الغزاة من قبل وصواريخهم من بعد، وهي تتململ في مرقدها على محاولات المخلصين من أبنائها لتحريك طاقاتا الكامنة واستعادة وعيها الحضاري وبحديد منطلقاتحا السامية. وأخذت هذه الجهود عدداً من المسالك، منها جهود دائبة مخلصة تعمل على تأكيد الهوية وإثارة مكامن الاعتزاز في الأمة وأبنائها بسرد سير غابر أبطالها وبناة حضارقا، والغوص في مكنون تراثها والكشف عن روائع نفائسه، التي أسهم بها في رفع بناء الحضارة الإنسانية، حين كانت الأمم تغفو في جهالتها، وتَشوُُهِ رؤاها الكونية، وخرافيةِ ثقافتها، وقصور فكرها.

وعلى أهمية ما قدم المصلحون والمخلصون من الجهود لرفع معنويات الأمة وإعادة الثقة النفسية لها في مواجهة الهجمة الشرسة عليها من أعدائها وما تئن تحت سياطه من وجوه القهر والغلبة وما يلحقها من تحطيم مقدرات الأمة، وعلى أهمية ما بذله ويبذله المصلحون من جهود ثقافية وسياسية وجهاد لإصلاح أداء الأمة وإرساء دعائم كياها، والحفاظ على هويتها، وعلى ما بذلوه وما زالوا يبذلونه من تضحيات للذود عنها ودفع عادية الهجمات الثقافية والسياسية والاقتصادية والعسكرية التي تتناوش جسدها كل يوم في كل موضع..إلاّ أنّ هذه الجهود المضنية - للأسى والأسف- لمُ تفلح حتى اليوم أن تكون على مستوى التحدي الذي تواجهه الأمة في إعادة صياغة العقل المسلم والنفسية المسلمة ليتحلى الإنسان المسلم بصفات إنسان الاستخلاف، منقذاً للأمة الإسلامية من محتتها لتعود رائدة للإتقان، ومبدعة للعمران، ومرشدة لنهج الحضارة 
ليس لحَمَلة رسالة الإسلام- على كل الأحوال- إلا مواصلة العمل والبحث والجهه لمعرفة الداء واستكمال النقص، لتكون الأمة على مستوى التحدي العلمي والحضاري الذي يطرحه الغرب والحضارة المعاصرة، وحتى يمكن للأمة أن تسلك مجدداً سبل القدرة والإبداع والإتقان والعمران، وأن بتحد هداية الإسلام، فتستطيع عند ذلك فقط أن تعرض على أمم الأرض وحضارته المعاصرة تحديها الروحي الأخلاقي الذي يجقق للإنسان بعده الروحي، ويبني فلسفة السلام الحقيقي والمعنى الكامل الخيّر للوجود الإنساني على هذه الأرض. ولن يتحقق هذا الهدف إلا إذا استكمل رواد الإصلاح والمخلصون من أبناء الأمة أداقم المنهجية والتسلح بالفكر الشجاع الناقد، الذي يتخطى الأساليب الدفاعية التي تقف في جوهرها عند حدود رفع الروح المعنوية للأمة، وإثارة روح المقاومة عند أبنائها في وجه الهجمات التسلطية المعادية الشرسة التي تستهدف مقومات الأمة وقواعد بنائها.

إنّ النظرة التحليلية النقدية المنضبطة هي أداة منهجية أساسية ومن أهم الأدوات الإصلاحية لدفع قوى النهضة والتجديد في فكر الأمة وأدائها، لأنّ النظرة النقدية هي في جوهرها نظرة إيجابية، تنطلق من موقع الثقة بالذات ومن رصيدها من الطاقات الكامنة والثروات الدفينة، إلا أنّ هذه النظرة لا تكتفي بعرض الإيجابيات، وإنما تتخطاها لمعرفة السلبيات والكشف عن العيوب والانحرافات لترشيد المسار وسد الثغرات واستكمال الأدوات. إنّ غياب النظرة النقدية الذاتية الشجاعة الجادة في فكر كثير من أبناء الأمة ومفكريها، وما يلاقيه فكر النقد والتمحيص من مقاومة ونفور، لا يسمح لصفوات الأمة بالحوار والتمحيص وتدقيق الأمور، ولا يعين جمهور الأمة على إدراك أوجه القصور وتلمس جادة الإصلاح، ويرجع ذلك في الأساس إلى الإحساس بالضعف والعجز والضياع، وهي أحساس زائف يجب ألا نقبله أو نستسلم له.

يجب على المفكر المسلم، والقيادي المسلم، والمربي المسلم، والمثقف المسلم، أن يوطدوا النفس بكل جد وصبر، وأن يرحبوا بكل شاردة وواردة من النقد البناء، الهادف إلى فهم أعمق وأشمل لحال الأمة وتحسس مواطن الداء في كياها، ما دام ذلك لا يكس ثوابتها من الإيمان بالله، وكتبه، ورسله، واليوم الآخر، ولا يعارض في شيء قصد الخير والعدل والإتقان والإحسان في الحياة والخلائق. 
هذه قضية فكرية منهجية أساسية يجب أن يتحلى بما مفكرو الأمة وصفواتما وعامتها، كما يجب أن تربي الأمة أبناءها عليها حتى يتكون فيهم حس الإتقان والإحسان والمسؤولية، ويقوم في نفوسهم ميزان الصلاح والإصلاح، وتعود نفوسهم على مقاومة الفساد ودرء الانحراف.

إن وقفة تأمل مخلصة بتعلنا ندرك أنّ الأمة لا تنقصها الموارد الخام البشرية والمادية، وأهّا غنية بالغايات والمبادئ والقيم الإسلامية السامية، فلابد من إرجاع قصور أداء شعوب الأمة إلى تشوهات الجانب الثقافي الذي ينتج في أساسه عن قصور مناهج الفكر وتشوهاته، والتي لابد أن تمتد آثاره على مناهج تربية أبناء الأمة وتكوين عقليتهم وبنائهم النفسي.

إنّ الاقتصار على النظر الجزئي في تتبع مظاهر قصور أبناء الأمة وشعوبها في الأداء السياسي والاقتصادي والتقني، وفي تخلف تنظيماتا ومؤسساتا، والانشغال بتفاصيل هذا القصور والتخلف، هذا المنهج الفكري القاصر لن يمكّن مفكري الأمة من إدراك كليات الأزمة التي تواجه الأمة وشعوبها، ولا من تشخيص أصل الداء، ومعرفة كوامن البلاء.

إنّ حركات الإصلاح الإسلامي قد تنادت إلى جهاد الإصلاح والتقويم منذ سقوط الخلافة الراشدة، وانتهى رجال مدرسة الخلافة في المدينة المنوّة إلى العزل والعزلة بعد أكثر من مائة عام من الصراع والمناجزة لدولة القبليات والعصبيات والنعرات وما تبعها من الاستبداد والمظالم والأنانيات، ليتضاءل دورهم في قيادة الأمة ووتوجيه سياساتها ومؤسساها وحركتها الاجتماعية، مما باعد بينهم وبين الواقع، وشوه بالضرورة إدراكهم لحركة الحياة والمجتمع. ولأكثر من ألف عام بعد أن بلغت العزلة والفصام بين الصفوة الفكرية والصفوة السياسية مداها، وخيم الجمود الفكري والاستبداد والتبديد السياسي على مقدرات الأمة، ولم يعد يخفى ما بلغته الأمة من التدهور والانخطاط، لم يستطع نداء المفكرين والمصلحين منذ صيحة أبى حامد الغزالي في القرن الخامس الهجري (الحادي عشر الميلادي) في "إحياء علوم الدين" وفي "هافت الفلاسفة" ومشروعاقم الإصلاحية الإسلامية الحضارية أن يحقق أهدافه العليا في غضة الأمة، والعودة بها إلى موقعها من القيادة

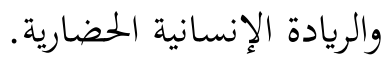


ولعل مشروع الإصلاح الإسلامي الذي قدمه عبد الرحمن الكواكبي في كتابيه: "أم القرى" و "طبائع الاستبداد" في بداية القرن العشرين، هو الأساس الذي ما زال الفكر الإسلامي المعاصر والحركة الإسلامية يدوران في رحاه بالوقوف عند عرض مبادئ الإسلام السامية في التوحيد والعدل والشورى والتضامن من ناحية، وفي تحميل الحكومات والصفوة السياسية مسؤولية تدهور الأمة وانخطاط أدائها من ناحية أخرى. ورغم مضي أكثر من قرن من الزمان على هذا المشروع، وقرون كثيرة على سواه من الدعوات والمشاريع، إلا أن مشروع الإصلاح الإسلامي لم يبلغ غاياته في هضة الأمة وتحريك كوامن طاقاتما على مستوى العصر والتحديات المطروحة فيه، بل إننا إن أخذنا نسبية حركة الإنسانية فهوَّة قصور أداء شعوب الأمة تزداد اتساعاً في ميادين العلم والتقنية والقوة والمنعة والعمران.

لذلك كان لا بد لمفكري الأمة من وقفة جادة تنظر نظرة نقد ذاتي شجاعة في أعماق الأمة وكليات كياها فيما وراء المفردات والتفاصيل والأعراض لمعرفة أصول الداء وكوامن الأدواء، وجوهر منطلقات

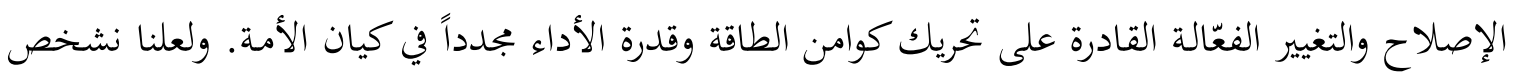
جوهر انحطاط الأمة وتخلف ركبها بأنه قصور أداء أبنائها وشعوبها في مختلف وجوه الأداء الحياتي الحضاري في السياسة والاقتصاد والمعرفة والعمران مع ضعف وازع الترابط الاجتماعي العام، وسلبية النظرة إلى الحياة بحيث لا يعدو المطلب في الحياة إلاّ البقاء وتأمين لقمة العيش، خلواً من التطلعات الإصلاحية الحضارية والإبداعية المعرفية العمرانية التي لا يكون للحياة الإنسانية معنى أو قيمة ذات دلالة استخلافية دوهما. والسؤال المحير هو كيف أمكن أن تتحول أمة الاستخلاف إلى هذا القدر من العجز والقصور والتراجع والتخلف، وإلى هذا القدر من التفكك والتنازع والتناحر، وإلى هذا القدر من القهر والفساد والاستبداد، وإلى هذا القدر من المهانة والحنوع والضياع!! للإجابة على مثل هذه التساؤلات لن يفيدنا التغني بالأبجاد الغابرة وحدها بل علينا بالدرجة الأولى الالتفات إلى ثقافة الأمة الحاضرة التي تنبئ عن واقع بناء عقليتها ومناهج تربيتها، وعن تكوين نفسية أبنائها، فالثقافة ومناهجها ومفاهيمها الممارسة في واقع الأمة هي الجذور التي تستمد منها شجرة المجتمع طبائعها الأساسية التي تشكل نوع ثمار أدائها، ومذاق عطائها، وقدرة أداء أبنائها، وبناء مؤسسات بجتمعها. 


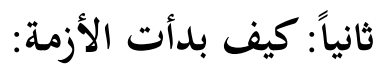

إنّ جوهر تراثنا الثقافي الذي يمثل خصوصياتنا والذي تمتد فيه جذور كياننا، هو بالدرجة الأولى الموروث الفقهي، بدءاً من عهد تكوين المذاهب الفقهية والفرق العقيدية، التي قام على بنائها ورصفها وتأليفها مثقفو الأمة وعلماؤها في عزلتهم السياسية العمرانية في دأب وإخلاص وبترد، مما أغنى حبكتها المدرسيّة، ورصّع رقعتها العلميّة بمفردات النفائس والتأملات الفكرية حتى أصبحت بفعل العجز والضعف مع ونع الزمن، سيفاً يمثّله خطاب الترهيب، وغشاوة على بصر الأمة، لم تعد معها ترى أصول الرؤية القرآنية إلا بلون هذه الغشاوة وما ناسب قوالبها، فإذا خالف ظاهر الكتاب والسنة قول الصاحب؛ تأول المقلدون نصوص رتس برك الكتاب والسنة ليوافق قول الصاحب.

فإذا أراد المصلحون حقاً إصلاح الأداء، والقضاء على أسباب قصوره وسلبيته، فإنّه لابد لهم -إلى جانب زمة انشغالاقم الكثيرة- من العمل الجاد على الإصلاح الفكري المنهجي وتنقية المدخلات الثقافية في نظام الأمة المعريف وفي مناهجها وأساليبها التربوية، وإعطاء هذه الاعتبارات والمنطلقات الأساسية الأولوية المناسبة في هذه المرحلة الأساسية الحرجة من جهود بناء القواعد والمنطلقات الإصلاحية. وإزالة التلوث الثقافي وتحقيق التنقية الثقافية أمر لا يحدث عشوائياً ولكنه يأتي ثمرة مناهج التفكير السليم التي توضح الرؤية وتكوّن

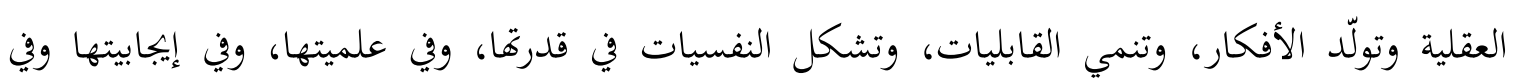
إقدامها وشجاعتها ومبادرتا، وتستنقذها من قصورها وخرافيتها، ومن سلبيتها وإحجامها ورهبتها. ومناهج الفكر إنا هي الأدوات التي يبنيها العقل ويرسم خطتها متأثراً بمنطلقاته ومفاهيمه وبيئته وحاجاته والظروف التي تحيط به، والتحديات التي تواجهه، فإذا تشوهت المنطلقات والمفاهيم، وإذا تغيرت البيئات والحاجات والتحديات والظروف التي تحيط بالإنسان، وإذا لم يقم المفكرون والعلماء بإعادة النظر في مناهج الفكر، وإعادة رسم خطتها لتستعيد سلامة المنطلقات ولتناسب البيئة، وتلبي الحاجات والتحديات، وتستجيب للظروف المستجدة المتغيرة أمام الأمة، فلابد أن تنشأ لدى الأمة أزمة فكرية خطيرة همدد كياها وتقضي على فرصها في الإصلاح والتجديد في حياتا. ولذلك علينا أن نتعرف على البيئة والظروف التي أحاطت بأرباب التراث الإسلامي والظروف التي أحاطت بهم أثناء بناء هذا التراث والمناهج الفكرية التي 
بنوها ورسموا خطتها حتى يمكننا في ضوء الظروف التي تحيط بنا، والتحديات التي تواجهنا، فهم وجوه الإحسان ووجوه القصور في ذلك التراث، وحتى يمكننا معرفة معالم خطة بناء المناهج التي تناسب بيئنا وظروفنا وإمكانياتنا والتحديات المطروحة على أمتنا، وحتى تكون هذه المناهج هادية لنا في جهودنا لتنقية الثقافة التي نقدمها لأبنائنا، وتصفية رؤية أصول حضارتنا ومعارفنا، بما يعين على حسن بناء عقلية أجيالنا ونفسياتم، وعلى بتحيد مؤسسات بجتمعاتنا وتطويرها بشكل جاد أصيل معاصر وفعّال.

\section{عوامل التغيير والانحطاط: - م}

لقد بدأ الإسلام -صفاء سماء الصحراء وتوهج كواكبها في حالك ظلام ليل الجاهلية- برؤية قرآنية كونية توحيدية فطرية سائغة، وقيم ومبادئ هادية تقصد إلى الخير والإحسان والإتقان، وتحيي الضمائر وتبني حس المسؤولية، وقد جسّد رسول الله عليه أفضل الصلاة والسلام هذه الرؤية وهذه الرسالة في قومه، وأقام نموذج بجتمع العدل والتضامن والشورى، وخاطب الناس على قدر عقولم، وأحسن بالحكمة والموعظة الحسنة خطابم ودعوتم، وساسهم بما يناسب أحوالهم، يوقر كبيرهم ويرحم صغيرهم، ويقيم العدل بينهم ويتولى بالعناية والرعاية ضعيفهم، ويحمي بالشوكة حقوقهم، وتابعته في ذلك حكومة خلفائه وأصحابه الذين آمنوا برسالته، من أبناء الجزيرة من العرب الكرام الأحرار في بيدائهم وأوكار نسورهم والعالمين من ورائهم، فخالطت

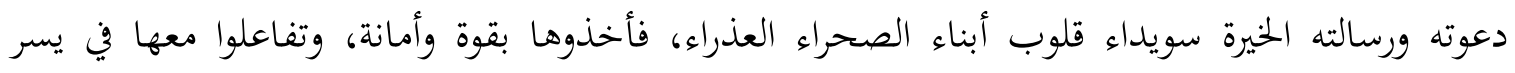
وتلقائية وحسن بصيرة، لينقي عقول من آمن منهم ونفوسهم من أدران الجهالة والوثنية، ويدفعها في حضارة

$$
\text { إنسانية سنية علمية إلى مدارج عليا من الاستخلاف والعمران. }
$$

ومع سرعة انتشار الإسلام وجدنا دولته وصلت واستقرت تخومها في سرعة غير مسبوقة ما بين شواطئ

بحور الظلمات، وحوت شعوبها صنوف القبليات والعصبيات والتقاليد والعقائد والأديان والفلسفات الأعرابية واليهودية والنصرانية والمجوسية والهندوكية واليونانية والرومانية، وانطوى تحتها وجاورها وتفرع عنها عديد من العقائد والفلسفات والثقافات، وقد صاحب هذا الانتشار تفاقم التحديات، وتراجع قبضة القادة والمعلمين والأصحاب العالمين العاملين المؤسسين وتراجع دورهم تدريجياً، بسبب تفاقم الأعباء وسطوة السنين وعادية 
الموت والفناء، وبتفاعل هذه العوامل كلها، مع محدودية الإمكانات البشرية القادرة على إعادة تربية أبناء هذه الشعوب الكثيرة الوافدة -وفي وقت قصير- إلى الإسلام، وتنقية ثقافاقم وتقاليدهم وتخليصها من تلوثات العنصريات والقبليات والأساطير والخرافيات ونوازع الاستعلاء والتظالم ومخلفات الجاهليات؛ كان لابد أنْ تختلط الأمور وتتولد الصراعات وتختلف الأهداف والغايات، وتطل رؤوس فتن العصبيات والعنصريات وبقايا التقاليد والفلسفات.

وبحكم تلاحق الأحداث وضعف الوسائل وجسامة التحديات التي واجهت دولة المدينة الناشئة في بجال التربية أمام سيل القبائل والشعوب الجارف التي دخلت في دولة الإسلام، والتي جُجندَّت -على ما علق بها من تراث الجاهليات- في مؤسساته وجيوشه، أدى ذلك كله إلى تحكيم السيف للفصل فيما أطل من صراع بين بقايا تطلعات زعامات القبليات والجاهليات، وبين بقايا أمناء مدرسة المدينة ورجال دولتها، وكان لا بد أن تلحق الهزيمة بالجمع القليل المسن المثخن، وأن يخلو وجه السياسة والسلطان وتصريف الحياة للعصبيات وزعاماها وأتباع المنافع وطلاهما، لينعزل أمناء مدرسة الرسالة ورجال الفكر والعلم والدعوة ويعزلوا في المساجد والزوايا للدرس والتأليف والتعليم والفتوى في خاصة شئون أفراد الناس وتبصيرهم بأصول عقائدهم وأداء شعائرهم، وما يديرونه من أمور عقودهم ومعاملاقمم، والحكم فيما ينشأ بينهم ويلجئون إليهم فيها من خلافاتم. هذا العزل والانعزال أضعف بالضرورة حسّ هؤلاء المثقفين والعلماء والدعاة بواقع تفاعلات المجتمع ومتغيراته وفعل عامل الزمان والمكان في تشكيل واقع الإنسان المسلم وتصوراته وتحدياته.

ولما كان واقع العلوم والمعارف، خاصة الإنسانية منها، ما يزال في مهده الحضاري، يسيطر عليه الفكر النظري والتيه الغبي الفلسفي والمنطق الصوري اليوناني، فلا عجب أن يلحق الغبش بالرؤية الإسلامية الاستخلافية، وبالمنطلقات العلمية السنية الفطرية الإسلامية، وأن يتسلل إلى الفكر الإسلامي منهجٌ فكريٌ يعكس هذه العزلة الاجتماعية والغيبة الفكرية، ويستجيب لواقعها لينتهي الأمر مع الزمن بالعلم والعلماء بأن يغلق فكرهم في حلقة مدرسية أكاديمية تدور في حلقات مفرغة من الدراسات النظرية النصية التاريخية، بُجِْْب معها القدرة على الاجتهاد والإبداع وبتحيد المعارف والمؤسسات وتطويرها. 
في هذه البيئة الفكرية النظرية القاصرة المغلقة لا عجب أن تتحول إلى حد كبير دراسات العقيدة، وبكل حسن النية، إلى مباحث معقدة وإلى سفسطة جدلية نظرية معزولة عن الواقع، عوض أن تكون قاعدة فكر المجتمع ودليل حركته وأساس رؤيته ومبادئه وقيمه التي تنبثق عنها نظم المجتمع ومؤسساته وقوانينه وأحكامه. ولا عجب أيضاً أن تنشأ في هذه العتمة العقيدية الفكرية، منهجية فكرية مدرسية جزئية، تبنى على المتابعة والتقليد والمحاكاة، تتجمد فيها الصور وتثبت فيها المتغيرات، ويمحى فيها الزمان والمكان، ويهمش في فلكها المغلق كل عقل نير وفكر شجاع مبدع.

ولا عجب أيضاً في هذه البيئة الفكرية النظرية المغلقة أن تتشوه الرؤية الإسلامية الكونية فيغيَّب البُعد العام في طرحها وتخيم السلبية على هذا الطرح لتحظى الشعائر وأعمال الذكر بشرف لقب "العبادات"، ويهون من شأن جهاد الحياة وأمانة إدارة دفتها، وواجب الاستخلاف والعمران فيها ليتقلص ويهون من شأنه بمسمى "المعاملات". ولا عجب في بيئة هذا الفقر الفكري أن يقع الفكر النظري المعزول في وهم التعارض بين "العقل" و"النقل" حيث يكون العقل في كثير من جوانبه فلسفات توهمات وسفسطات، وحيث يكون النقل في كثير من وجوهه تقليداً ومحاكاة، وتدور رحى العلاقة في كثير من الحالات في عالم الأوهام خارج نطاق الزمان والمكان. لا عجب أن يُهمّش المبدعون ويحاربوا، ولا عجب أن تخمد طاقة الدفع والتجديد وكوامن القوة والإبداع، دون أن تغني عنها تراكمات الصنائع في دفع عوامل التمزق والانخطاط واهيار الحضارة

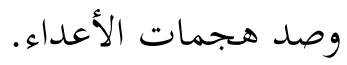

لا عجب على وجه الخصوص -في بيئة هذا العجز الفكري والحضاري- أن تتمزق ثقافة الأمة وتتوزع ويضعف ارتباطها بالزمان والمكان، وأن ترى في المكان -على امتداد بلاد الإسلام- أثر الأساطير والخرافات والتقاليد الموروثة من ثقافات شعوب المسلمين طاغية حتى تكاد تمزق وحدة ثقافة الأمة وبتعلها كالثوب الخلق المرقع، وأن ترى في الزمان عزلة ثقافة العلماء المدرسية ومصطلحاتها وقضاياها (التاريخانية) عن واقع ثقافة العامة الساذجة الخرافية والسلبية الاتكالية من جانب، وعزلتها عن واقع ثقافة المدنيين والمتغربين الذين يسيطرون على إدارة المجتمعات المسلمة ونظمها السياسية من جانب آخر، بحيث لا تتواصل ثقافات 
النخبتين ولا تتلاقح أفكارهما، ولا تتكامل قواهما، بل تتعارض وتتعادى على غير هدى ومنهج، وتصبح حصيلة جهودهما حصيلة سلبية، يلغي بعضها بعضاً، مما يزيد من ضعف الأمة وتمزقها وعجزها.

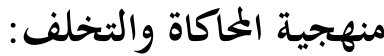

لا يكفي أن نتبين ما أصاب الرؤية الكلية من تشوهات غاب معها الجانب العام للحياة والمجتمع وسيطرت فيها النظرة السلبية إلى الحياة بتلخيص أداء الإنسان فيها بعبادات دينية ومعاملات دنيوية، بل لابد لنا من معرفة سمات المنهجية التي نجمت وبتحاوبت مع هذه الرؤية الشائهة والمعارف القاصرة، لأن عدم معرفة ذلك سيبقي تصوراتنا وخططنا الحياتية حبيسة تلك الرؤية القاصرة والمنهجية المشوهة.

لقد كانت الطبيعة التاريخية لتلك البيئة الفكرية والمعرفية التي اتسمت بالعزلة والروح النظرية البعيدة عن الواقع؛ طبيعةً نقلية تتنكر في كثير من الوجوه للعقل وتتصارع معه في معركة لا تنتهي، لأغها انتهت في كثير من جوانبها إلى أن تكون عقلية منغلقة وثقافة خابية، لا تملك الرغبة ولا الوسيلة لاستخدام العقل للبحث والتنقيب في الطبائع الإنسانية والسنن الكونية والأحداث الزمانية والمكانية. لقد عجزت تلك المعرفة النقلية عن إدراك موضع هداية الوحي والإرشاد الإلهي الخاصة بالطبائع والسنن، ومواصلة توسيع السقف المعريف والحضاري الإنساني على مر الزمن، من أجل احتواء المتغيرات، والاحتفاظ بتوازن المجتمعات ونموها وقدرتا وأدائها في حلبة السباق بين الأمم.

والمنهجية النقلية المنغلقة هي في جوهرها منهجية جزئية تعني بالمفردات بعيداً عن إطارها التاريخي ومحتواها البيئي، وتتجاهل السنن الكونية والعوامل الزمانية والمكانية المؤثرة فيها. وإذا كان المنهج الجزئي يعتمد أساساً على أداة القياس لفهم مفردات الحوادث؛ فإنّ هذا المنهج لا يمكنه أن يستقيم حين تنمو الإمكانات وتتغير التحديات ويتسع السقف المعرفي ويتراكم فهم الإنسان للسنن الكونية، حيث تتغير تبعاً لذلك الصور الكبرى وتتغير طبيعة المجتمعات في الزمان والمكان. ولمعالجة هذا القصور المنهجي لجأ بعض العلماء من وقت مبكر إلى سد شيء من هذه الثغرة، وذلك بتطوير أداة الاستحسان حين يفشل أداء أداة القياس على الرغم من ظاهر سلامة الحبكة الفنية وذلك بالرجوع إلى روح الشريعة، والاستحسان على أساسها، إلى أن يهتدي الباحث إلى ما يقبله حسه الكلي لروح الشريعة. وحتى هذا القدر من المبادرة لتلافي آثار عجز فكر العزلة 
وآثار غياب الدراسات الاجتماعية لفهم السنن والطبائع، فإنه لم يكن سهلاً التسليم لهذه الأداة واعتماد مرجعيتها في تلك البيئة التي أصبح الفكر المرجعي فيها فكراً نقلياً يوغل في طلب النص ولو كان ضعيفاً، ويركب في سبيله الصعب طلباً لراحة التقليد والمحاكاة في تلك العزلة الاجتماعية والصورية المعرفية.

وإذا كانت نقلة مقاصد الشريعة كإصلاح منهجي كلي يهدف إلى إخراج الفكر الإسلامي من عزلته والقفز فوق المفردات إلى كلية الصورة والعوامل المؤثرة فيها، إلا أنّ هذه النقلة الإصلاحية لم يكتب لها النجاح الكافي في إخراج الفكر الإسلامي من نقليته وجزئيته، لأنّه لم يتسع مداها ومفهومها إلى أبعد من الدائرة النصيّة، ولأنه لم يلحق معارف العلوم الشرعية وثقافة العلماء شئ من التغيير في مجال دراسات العلوم والسنن الاجتماعية والكونية، على الرغم مما أصابمم من الفزع لما بلغته حالة الأمة من التدهور الذي كشفت عوارها هجمة أعدائها وقوة نمائهم، وفاعلية أداء مؤسساقم، ورفاهة عيشهم، وهكذا بقيت العلوم الشرعية وثقافة علمائها تدور في رحى العقل والمنطق الفلسفي النظري، خالية في جلها من معارف الدراسات الإنسانية العلمية في الطبائع والوقائع الكونية والحياتية، وما يلحقها من عوامل الزمان والمكان وحاجاته وإمكاناته وتحدياته، فكان لابد للمعارف والدراسات الشرعية ومدارسها أن تستمر في دوراها في إطار الفكر الجزئي حيث لا تعدو دراسة المقاصد الشرعية عن تجريد تلك الجزئيات النقلية وإعادة صياغة قضاياها بصيغ كلية لها

$$
\text { ذات المحتوى الفكري والدلالة (التاريخانية). }
$$

إننا إذا أردنا للنقلة المنهجية لمقاصد الشريعة أن تؤدي ثمرتا، وأن تمثل منهجاً كلياً في مجال علوم الشريعة، يتكامل مع المنهجيات الجزئية؛ فلابد من تغيير المحتوى المعرفي لمناهج الدراسات الإسلامية (علوم الشريعة) بشأن مجالات الحياة لتجمع إلى جانب الكلي والجزئي جانب النص بعد تمحيصه سنداً ومتناً في ظل حاكمية القرآن الكريم، كما تضم إلى جانب نفائس التراث جانب المعارف الإنسانية في الطبائع والسنن الكونية مناهجها وثمرات دراساتما العلمية التجريبية في الزمان والمكان، لأنّه دون هذا الجمع والتوحيد والتلاقح لا يسهل الافادة الراشدة المنهجية من كليات هدي الوحي في توجيه مناشط الحياة ومؤسساتما وخطة عمراها بشكل فعّال مؤثر. 
والسؤال المهم الآن هو كيف أثّرت هذه البيئة العلمية المغلقة المنعزلة، وهذه المنهجية النقلية الجزئية على مناهج التربية في الأمة وفي تكوين عقليتها وبناء نفسية أبنائها؟

لقد سبق أن أوضحنا أنّ بيئة الفصام بين نخبة العلماء ونخبة السلاطين وعزلتهما عن بعضهما البعض أورثت الفريقين عدم القدرة على إدراك المتغيرات والتفاعل معها وتطوير الوسائل المناسبة لاحتواء المتغيرات والمستجدات، ولذلك لجأ كل من الفريقين -بغض النظر عن النوايا- إلى الإرهاب والعنف للتحكم في الموقف، لأنّ استخدام القوة والعنف هو حيلة العاجز المأزوم المضطر، وهذا يفسر لماذا كان جلّ تعاملات الصفوات السياسية مع الفئات المعارضة والمتمردة والثابة في تاريخ الأمة وما يزال هو إرهاب الاستبداد والتنكيل بالمعارضين والمتمردين وطلاب الإنصاف والتغيير والتجديد والتطوير، وهو يفسر أيضاً لماذا غلب على خطاب كثير من رجال الصفوة العلمية الدينية خطاب الترهيب والتهديد والوعيد، وتلبيس جلّ الخطاب الديني بالمسحة المقدسة وتصيد النصوص وليّ أعناقها، بسبب الغفلة أو الغرض إن لم يكن تدليسها، وذلك للتذرع بها في الخطاب لإلغاء دور العقل والمعرفة الإنسانية في التيقظ وامتحان سلامة الخطاب وصحة مأخذه، كما يفسر ذلك العجز في كثير من الأحيان الإغراق في التعقيدات النظرية والفلسفية والمدرسية التي يحجب دخاها رؤية جمهور الأمة ويدفع قطعاها المرهبة الساربة إلى الخضوع سياسة والتقليد ديناً، والخرافة والشعوذة اعتقاداً، والعجز والتواكل سلوكاً وفكراً وتدبيراً.

كذلك سبق أن أوضحنا أننا ورثنا بسبب الفصام وما ترتب عليه من العجز وعقلية المتابعة والمحاكاة التراثية المعرفيّة، أن تضخم دور النص على حساب المعرفة الإنسانية التي خبا حظ العناية العلمية والبحثية فيها، والتي لم يعد لها بشكل حي في ضمير الأمة بُعداً روحياً، وأصبح التحصيل الديني في المدارس الدينية المتخصصة ينحصر في استظهار النصوص والمتون لتندثر في التربية والتعليم طاقات المبادرة والإبداع، ولينمو بسبب الإرهاب التربوي و (التاريخانية) المعريّة سرطان الخوف والخنوع والتقليد، ولتتسع الهوة بين ثقافة الخاصة الفلسفية النظرية المعقدة وبين ثقافة العامة الغارقة في الأوهام والخرافة والاتكالية وغيبوبة فاسد التصوف. وحتى وقت قريب وقبل أن يشيع نظام التعليم الحديث، رغم عيوبه الكبيرة الكثيرة في بلاد العالم الإسلامي، لم يكن هناك من الثقافة والتعليم لعامة الأمة غير شيء من حفظ القرآن وشيء من علم الحساب اللذين كان 
التدريس في الكتاتيب يقتصر عليهما، مع شيء من الترغيب والترهيب في مواعظ صلوات الجمع وما تيسر من حلقات الوعظ والذكر في الزوايا والمساجد.

إنّ من المهم لكي ندرك مدى التخلف المعريف لثقافة جمهور الأمة وقصور أدائه، وتشوه بنائه النفسي والمعرفي، أن نعلم أنّ جل الوصايا التي وجهت إلى المؤدبين في سالف تاريخ الأمة بشأن مراعاة الرفق في تعليم الصبيان وحسن تعليمهم وتثقيفهم، إنما كانت وصايا موجهة إلى المؤدبين القائمين على تعليم أبناء الخاصة من علية القوم الذين يقومون بتعليم أبنائهم في دورهم، وليس شيئُ من ذلك شائعاً في مفاهيم تربية أبناء عامة الأمة في الكتاتيب وممارساتما التي كان سوء حالها وضآلة معارفها وانحطاط مستوى قدرة معلميها موضع النقد من القلائل من العلماء والمفكرين الذين عنوا بالحديث عنها ووصف سيء أحوالها.

وخلاصة ما تقدم هو أن تشوه الرؤية الكلية الإسلامية قد أسهم في تكوين ثقافة وأدبيات فقهية وتربوية فردية سلبية، كما أنّ العزلة الاجتماعية والفكر النظري أسهما بدورهما في تكوين عقلية نقلية ذات منهجية جزئية صبغت التربية والتعليم بطغيان الجانب المعلوماتي النصي المبنى على الاستظهار والمتابعة والتقليد، هذا العجز المعرفي أورث بدوره مناهج التربية عدم القدرة المنهجية على السبر العلمي لأغوار الجانب النفسي والعناية التربويه في بناء الكيان النفسي والوجداني للناشئة وتمكينهم من تملك ناصية القدرة على ركلى الأداء الإيجابي وتنمية قدراتم الإبداعية والحضارية.

ثالثاً: طريق الإصلاح الإسلامي الحضاري:

لقد حضّ القرآن الكريم الإنسان على إعمال الفكر وحذّر من المحاكاة والمثابعة العمياء، وحضّ على التفكر والتدبر في الكون وسننه وآياته، والسعي في إعمار الأرض بالعدل والإحسان والإتقان. ولم يكن عبثاً أن جاء القرآن الكريم هداية في كليات الحياة في الغيب والشهادة، ولم يفصّل إلا فيما هو من ثابت السنن والطبائع، ولم يكن عبثاً أنّ رسول الله صلى الله عليه وسلم قد أوضح للناس أن ينفذوا أوامره إليهم باعتباره 
الحاكم المدبر للشؤون العامة للمجتمع، وألا يحتجوا بأنّ تلك الأوامر والتوجهات السياسية والاقتصادية والإدارية لم ترد في القرآن، لأن القرآن ليس كتاب تعليمات إدارية وميدانية فهو موِّه وليس مدبراً.

ولذلك فهى الرسول صلى الله عليه وسلم الناس عن الكتابة والتدوين لأقواله وتعليماته وأوامره وتوجيهاته في إدارة شئون الدولة والمجتمع لأها تتعلق في كثير من وجوهها بظروف زمانية ومكانية، فلا تختلط هذه الأقوال والتعليمات والأوامر والتوجيهات بنص الهدى القرآني الُمَجهه إلى أصل طبع الإنسان وحاجته في كل زمان ومكان، وليس تعليمات سياسية إدارية زمانية مكانية، ولو كانت أقواله صلى الله عليه وسلم مثثابة القرآن لما فىى عن كتابتها. ولو كان لمما ذات الدرجة والغاية القرآنية لكانت هذه الأحاديث واجبة الحفظ بذات القدر وما أعوز رسول الله صلى الله عليه وسلم، وهو مؤيد بالوحي، أن يوجه الأمة إلى أسلوب الحفظ المطلوب.

وعلى أي حال، فإنّه حسب زعم من يسوون بين القرآن والسنة لم يكن، على أسوأ الظروف، ضير أنْ يختلط شيء من هذه الأحاديث -وهي وحي له نفس الدرجة والغاية في زعم من ادعى ذلك- بالقرآن الكريم، وهذا فهم غير صحيح ونتائج غير مقبولة، وقد تسبب هذا الفهم في كثير من الخلط والغبش الفكري والمنهجي، عانت منه الأمة، وما تزال تعاني، في سبيل إحياء علوم دينها وحضارتا وقدرقا على حمل رسالتها الإسلامية العالمية على اختلاف العصور والبلدان. وهو من ناحية أخرى زعم يجعل حفظ الحديث النبوي التشريعي وتنزيهه على الخلط والكذب على شاكلة ما تم في حفظ الوحي القرآني، بشكل أو آخر، أمراً أعجز الله ورسوله وحاشا الله ورسوله عن مثل هذا الزعم والوهم.

ولذلك ليس عبثاً حرص الخلفاء الأصحاب ألا يتداول الناس مرويات أحاديث رسول الله صلى الله عليه وسلم خشية أن يصرفوها إلى حال غير الحال المعنية هما على عهد رسول الله صلى الله عليه وسلم، وألا يدركوا أبعادها الزمانية والمكانية، أما ما تحتويه من المبادئ والأصول المفاهيمية فلا خوف عليها، فمرجعها

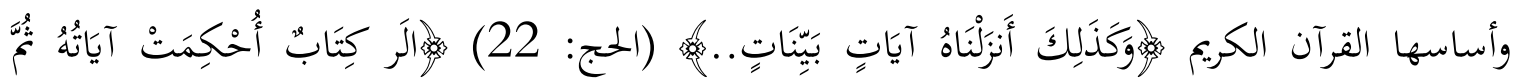

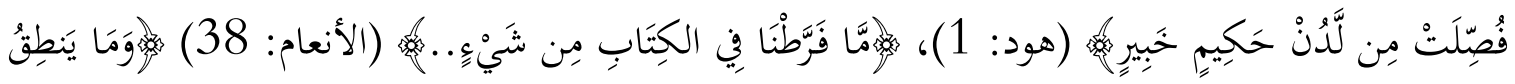

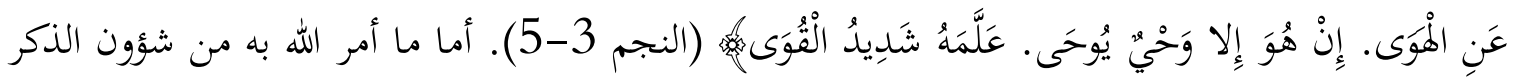


والشعائر في الصلاة والزكاة فقد حفظها الله وجاءت سناً فعلية متواترة امتثالاً من الأمة لأمر الله، حين ردّ أمرها وأمر أسلوب أدائها إلى رسوله الأمين وأفرده في ذلك بالأمر بآية من القرآن الكريم: آلَأَوَقِيمُوا الصَّلاةً

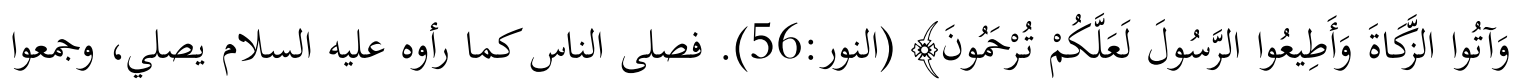
الزكاة كما جمعها. أما شؤون إدارة المجتمع وسياسته فقد وكل ذلك إلى رسوله وإلى خلفائه من ولاة أمر

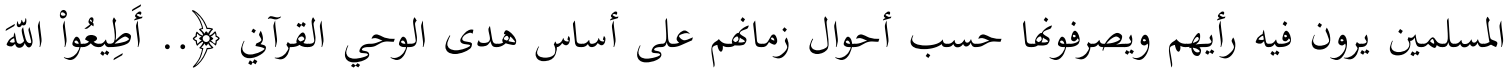

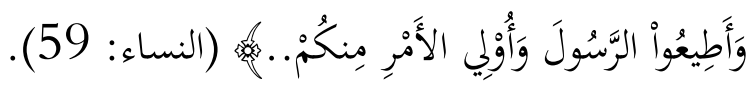

وليس عبثاً أن يجتهد الخلفاء الأصحاب على قرب عهدهم برسول الله صلى الله عليه وسلم في كثير من أحوالهم على غير ظاهر شبهـا بأحداث السنة النبوية، وعلى غير قياس عليها لما يعلمونه من تغير الأحوال ومدلولات الأحداث، وبذلك يكون القصد هو النظر والاستئناس والاهتداء بالسنة النبوية فيما صدر عنه صلى الله عليه وسلم في شؤون إدارة الأمة وسياستها وتوجيه أمورها، أو ما يتعلق بحال الإنسان. ولحق اجتهاد الصحابة رضوان الله عليهم بكل ما يتصل بتوثق سند الروايات وعرض متنها على مقياس القرآن الكريم في كلياته ومقاصده، وما يتصل بالنص من ملابسات الزمان والمكان، لفهم الدرس والحكمة النبوية لما صدر عنه صلى الله عليه وسلم من أمر وتوجيه فيما واجهه من شئون زمانية ومكانية، وما أخذ به نفسه وخاصة أهله من أمر، وكيف اجتهد فيه ونزّل عليه المقاصد والمبادئ والمفاهيم، وأي تاون في أي شيء من هذا المنهج في تناول السنة النبوية، مهما حسن القصد وخلصت النية، لا ينجم عنه إلا غبش وخلط فكري وانتهاك وسوء استخدام للقدسية في نفوس المؤمنين.

وليس من المستغرب بعد أن اعتزل رجال العلم والمعرفة وطلاب الصلاح والإصلاح، وعُزلوا سياسياً واجتماعياً واقتصادياً في المساجد والزوايا والمدارس، أن يتفرغوا ويلجأوا إلى جمع كل شاردة وواردة مما نسب إلى النبي صلى الله عليه وسلم وأصحابه من حديث وسنة، يستقون منها المعرفة -وبمنهج جزئي - وجلّهم في تيه الغيبة الاجتماعية وغيبة الممارسة السياسية والإدارية، وقلة الخببرة والدراية بالسنن والطبائع والوقائع الاجتماعية، وأن يتوسع الرجال في الجمع، وأن يتجرأ الكثير منهم على الرواية على ظاهر ضعفها والتي يزداد 
مع مرور الزمن استعصاؤها على الضبط والتدقيق وفحص حال السابق من رجالاتا، في عصور عصفت بها الصراعات والفتن وازداد معها ترهيب العامة والمعارضين بإشهار سيف القدسية على هذه الروايات.

وليس من المستغرب أن يزداد مع الزمن في واقع القصور المعرفي الاجتماعي الاقتصار على محاكاة الصور التاريخية وتصوراتا، والرغبة عن إعمال الفكر والتجربة والتحليل والنقد، والاجتهاد، والاكتفاء بالنصوص المغلفة حقاً أو باطلاً بالقدسيات. وأصبح كثير من موهوم هذه النصوص وضعيفها ومدخولها في كثير من الأحيان باباً إلى الخلط والتشويه والشعوذة خلف ستار من موهوم الصدق والقدسية المزعومة، ولتصبح بعض الألفاظ على غير سياقها ولا كلية دلالاتما مشجباً تعلق عليه أساطير الأمم وخرافاتما ومنحول النصوص وأوهامها وسوء التأويل وصرف المعاني عن غاياتما وثوابتها القرآنية.

لكل ما سبق ولما يمثله واقع حال الأمة وثقافة عامتها، وما خيّم على فكرها من الجمود والانططاط في عصورها المتأخرة، فإنّ الأمر يستدعي من أهل العلم والفكر والثقافة العمل الجاد لحماية دين الأمة وثقافتها وفكرها، من أن تستخدم مصادرها -وخاصة الموهوم من نصوص السنة ومرويات الأحاديث وجزئية مأخذها- لتكون مشجباً تعلق عليه أوهام النفوس وفكر الدجل والشعوذة. إن هذا الاستخدام -أوسوء الاستخدام بعبارة أدقّه- أسهم في قتل في الأمة تلك الروح العلمية والطاقة الإبداعية، التي تستند إلى الرؤية الإسلامية الكونية وما سخره الله للإنسان من قوى السنن الكونية، في الوقت الذي انتعشت فيه هذه الروح لدى الأمم الأخرى ففاقت في إمكاناتا وإبنازاتا في واقع عالمنا تهويلات الجهلة والدجالين والمشعوذين ورواة

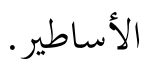

إنّ القدسية طاقة روحية إيجابية هائلة لا يصح في عتمة الروح الصورية المدرسية وتراث الأساطير والفلسفات الجاهلية أن تصبح وسيلة لقهر العقل والضمير المسلم، ولا أن يتحول معها رجال الفكر والثقافة الإسلامية حراساً للتخلف في فكر الأمة وثقافتها ومعوقين لتحررها وانطلاقها، ولاستعادة القدرة على حمل

إنّ سلطة القهر باسم القدسية هي نقيض لهداية القدسية، وهي من أهم مظاهر الديانات والثقافات المتحجرة التي تفسر هيمنتها على النفوس انخطاط شعوبها وهمود طاقاقم، وتخلف فكرهم وأنظمة حياتم، 
بحيث يصبح المقهورون هم أنفسهم حراس سجوفم وتخلفهم، وانخطاط فكرهم وبجتمعاقم. ولعل مكانة مئات الملايين من المنبوذين في مجتمع الديانة الهندوسية مثال مروع يوضح كيف يمكن أن تسخر القداسة لتكون أداة قهر الإنسان وتخلفه وظلمه، وأصبح المنبوذ في سلم الطبقات الهندوسية -من خلال آلية وهم تناسخ الأوراح- حارساً لسجن مهانته وظلمه واستعباده. بهذه الصورة أسئ استخدام جلال القدسية ورهبتها، لتصبح أداة قهر وإرهاب جبارة، تسحق الضمير وتدمر العقل، وتميت الثقافة، وبحعل من أتباعها وحملتها حراساً على آفاقم وتخلف أمهم وشعوبهم، وأداة لضعفهم وانحطاط حضاراتم وكسر شوكتهم.

على الرغم من الجهود المضنية المخلصة، التي أثمرت نظرات وتأملات واجتهادات جزئية ذكية، وأفادت في الاستجابة لكثير من حاجات العصور السالفة وأقوامها، فإنّ ذلك العطاء وتلك النظرات الجزئية الذكية لم تكن كافيةً -بسبب هذه البيئة الفكرية النظرية المغلقة- لتجديد طاقة الأمة واستعادة قوة الدفع وعناصر النهضة الاستخلافية في كيانا في عالم اليوم. لقد كان الإشكال الأكبر لهذه البيئة الفكرية المنعزلة المنغلقة أغا كرست لدينا وورتثنا الرؤية الكلية المشوهة التي أنتجتها عزلة الفكر والعلماء وإبعادهم عن توجيه الحياة العامة وسياستها في مجتمعات وعصور سالفة، عانت من تغييب البعد العام في كيان المجتمع وأدائه، مما أدى إلى أن تتسم شخصية الإنسان المسلم ومناهج تربيته وتكوينه النفسي بالفردية والسلبية والحنوع، فلا ترى في مؤلفات الفقه -التي ترسم صورة الحياة ومناشطها- جانب الحياة العامة بأبعادها وأهدافها ومبادئها ومؤسساتا، فقد كرئ أصبح الفكر ينصب في مجمله على الجانب الفردي فيما أطرّ باسم مصطلح "العبادات" ومصطلح "المعاملات" التي تتعرض جوهرياً إلى الأحكام والضوابط المتعلقة بـ "الذكر" و"الشعائر" وعقود المعاملات الفردية. وذلك أن الجانب الفردي أصبح هو مجال التأثير والنفوذ الفكري والديني للمفكرين والعلماء بعيداً عن شؤون الجماعة في مؤسسات الحكم والسياسة والعمران.

ولم يقتصر أثر هذه العزلة في تشويه الرؤية الكونية الاجتماعية الإسلامية على إهمال الحياة العامة في فكر الأمة وضميرها وتربية أبنائها، بل إن هذه العزلة الفكرية البائسة عن غايات الحياة والسعي فيها مع ما صاحب ذلك من علوم إنسانية نظرية فلسفية لاهوتية مشوهة، أعطت ثمارها المرة في تشويه الرؤية الإسلامية الكلية وتبلور ذلك في اختراع واستحداث مصطلحئ "العبادات" و "المعاملات" اللذين شاعا في تصنيف رده 
كتب الفقه الإسلامي حيث أصبح يطلق على "الذكر" و "الشعائر" مسمى "العبادات"، مع أفما في أصل الرؤية الإسلامية الكلية يستهدفان بُعداً روحياً يستحضر الضمير والمسؤولية في كيان الفرد المسلم وفي اتصاله بالله تعالى، من أجل حفز قواه الإيمانية إلى العمل الصالح والجهاد المخلص في جوانب الحياة المختلفة: في تزكية النفس، وطلب العلم والمعرفة، وكسب الرزق وإعمار الأرض، ونفع الخلق، ونشر الدعوة، وحماية ديار الأمة، ونصرة المستضعفين. وما يتبع ذلك من وجوه السعي المخلص في الحياة بالنفع والخير، وعلى النقيض من ذلك أصبحت الحياة والعمل في الرؤية الفقهية المدرسية السائدة هي ججرد "معاملات" دنيوية، تكاد تكون مجردة من صبغة الدين والجهاد والسعي بالخير والإصلاح رغم أنّ المقصود بالسعي بالخير في الحياة في أصل الرؤية الإسلامية أنه لب الامتحان الدنيوي وجوهر التوجه الإرادي للإنسان بما يصحبه من نية (إنما الأعمال بالنيات)، ومن جد واجتهاد (وأنّ ليس للإنسان إلا ما سعى)، يصح ذلك حتى في لذة البضع ومواضع رغبات النفوس وشهواتها.

إنّ الرؤية القرآنية ومصطلحاها لا تتحدث عن "عبادات" و"معاملات" ولكنها تتحدث عن إمان وعمل صالح، أي عن إيمان توحيدي يؤدي إلى العمل وأن يكون العمل صالحاً، والعمل الصالح في الرؤية القرآنية لا يتعلق فقط بالمقاصد والنيات في كل عمل من أعمال جوارح الإنسان بل يتعلق أيضاً بالاجتهاد والإتقان في إصابة وجه السنة الكونية في الأمر. ${ }^{1}$ أما العبادات والشعائر وما يجري مجراهما من الصلوات والصيام والحج والزكوات والصدقات فهي ذكر لله واستحضار للعلاقة به وبالدار الآخرة وحوافز للجهاد في الحياة بكل أعمال الجوارح وفي حسن أدائها وفق السنن الكونية.

إنّ الرؤية الإسلامية بالضرورة رؤية كلية شمولية تتأسس في جوهرها على الإيمان بالله واليوم الآخر، وهما ميزان إخلاص النية قصد الخير في العمل في هذه الدنيا، وحتى يكون عمل المسلم صالحاً نافعاً، تزكو به نفسه، ويتبوأ به مقام الصدق والنعيم الأبدي في الملأ الأعلى، لا بد من إخلاص النية والقصد، ولا بد من الاسترشاد بالسنن الكونية والالتزام بها. وقد تشوهت تلك لرؤية الإسلامية الكلية سبب ما تعرضت له الأمة

1 1 العمل الخطأ ولو خلصت فيه النية لا يعتبر صالحًا رغم أن لصاحبه أجر نيته في الآخرة، فالإصابة في العمل وخلوص النية شرطان

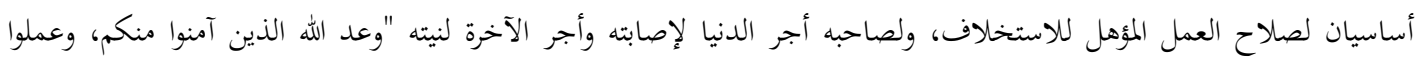
الصالحات، ليستخلفّنهم في الأرض كما استخلف الذين من قبلهم" (النور: 55). 
من الظروف والعوامل الاجتماعية والمعرفية وخبت نتيجة لذلك جذوة الإيمان والتوكل والإتقان وفقدت فاعليتها في صياغة الحياة ومؤسساةا ونشاطاةها، وذبل ضمير الأمة، وضعفت عنايتها بشئون الجماعة وسد ثغراتما ورعاية حاجاها وحاجات ضعفائها، وأن يخنع أبناؤها، وأن تتفكك عراها، ويتمزق نسيج وحدةا، ويفشو النزاع والتناحر بين أبنائها وشعوبها وأقطارها، وأن تصبح من سماتها السلبية والاتكالية وموت طموحات المعرفة والإتقان والسياحة الإيمانية المعرفية في الأرض، وأن تنصرف معارفها عن طموحات التمعن في آيات الطبائع والسنن في الكائنات، والجمع بين قراءة آيات الكتاب وآيات الكون، لتصبح لقمة البقاء -

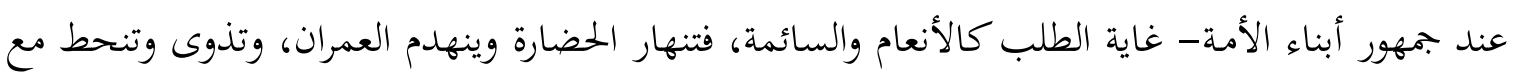
الزمان بدائع الصنائع، ويشيع الجهل، ويخبو الإبداع والعطاء، وتذل البيضة وتتخلف الأمة عن ركب

$$
\text { الحضارات والأمم. }
$$

إننا إذا أردنا أن نقوم بإصلاح حقيقي تربوي فلابد لنا من إعادة النظر في رؤيتنا الإنسانية الحضارية بحيث تستعيد الأمة ويستعيد أبناؤها الجانب العام والجماعي في التضامن والتناصر بين أبناء الأمة في الأهل والجوار والوطن والأمة والإنسانية، وأن نعيد إلى حياة أمتنا وتنظيماتا ومؤسساتما الاجتماعية على كافة المستويات توازن الأبعاد الجماعية والفردية، كما نعيد إليها إيجابية الاستخلاف وروح جهاد الذل والاتقان والاحسان.

على مفكري الأمة وعلمائها أن يعيدوا النظر في منهجية فكر الأمة بحيث نعيد التوازن فيها بين دور النص للاستجابة للهاية الإلهية والإفادة من إيجابيات مفردات التراث وعبَبرِ التاريخ ودروسه، وبين دور العقل والمعرفة الإنسانية في معرفة الواقع وفهم العلل والطبائع الكونية في الأنفس والمجتمعات والكائنات لتسخيرها، وتنزيل مواقع المدي الإلهي منها موقعها الصحيح في ترشيد الغايات والقيم والمفاهيم والأنظمة والممارسات، وتفعيل طاقات الإممان ووازع الضمير وحس الجهاد والمسؤولية في أداء الفرد والمجتمع.

كما يجب على مفكري الأمة وعلمائها أن يعيدوا النظر في منهجية البحث والدرس والنظر العلمي والمدرسي لنتخطى المنهجية الجزئية النصية إلى المنهجية الكلية التحليلية المنضبطة التي تضع المفردات وأدوات 
النظر الجزئية في موضعها الصحيح بحيث يحيط الناظر بكليات الأوضاع والحالات والقضايا والطبائع، ويضع مفردات مكوناتها في موضعها الصحيح، وبأوزاها الصحيحة في سياقها الزماني والمكاني المناسب. لابد للأمة من استعادة رؤيتها التوحيدية الكونية القرآنية وإصلاح مناهج تفكيرها وتربيتها للتخلص من أمراض السلبية والاتكالية ومن قصور الأداء، والتخلص من أمراض الفردية والتمزق والصراع، لتنتهي الأمة إلى نور الهداية، وعز العطاء، وقوة الوحدة والعلم والإبداع.

لابد لنا من تنقية ثقافتنا ومكوناتما من الضلالات والخرافات والشعوذة والخزعبلات، وهذا لا يكون إلا بإصلاح المنهج الفكري أولاً بحيث يعتمد الوحي والعقل والكون مصادر معرفته، كما يعتمد الأساليب المنهجية الشمولية التحليلية المنضبطة وما يتبعها من أدوات تناسب كل بجال معريف أداة لتوليد معرفته

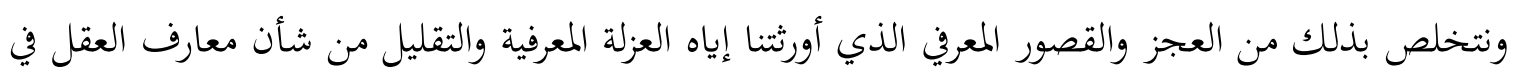
جوانبها الإنسانية والكونية التطبيقية. وبهذه المنهجية نستطيع أن ننقب في تراثنا الفكري لانتقاء نفائسه وإسهاماته الإيجابية، ونتخلص من أخطاء توهماته وانخرافاته.

إذا استقامت العقيدة والرؤية الكونية قرآنياً، وإذا استقامت إسلامياً وعقلياً وسننياً مناهج الفكر ووسائله وأدواته، يمكننا عند ذلك فقط إصلاح بناء مناهجنا التربوية والتعليمية التي تمكننا من إعادة البناء النفسي والوجداني للأمة وإصلاح مناهج تعليم أبنائها، بحيث يتحلى المسلم نفسياً ووجدانياً ومعرفياً بالصدق والشجاعة الأدبية والأمانة والجرأة الفكرية والإبداع والقدرة العمرانية. فمن خلال سلامة الرؤية وسلامة منهج الفكر نستطيع أن نقضي على خطاب الإرهاب وأساليبه، في مناهج تربيتنا وتعليمنا، من الناحية النفسية والوجدانية، وأنْ نقضي على منهج التقليد والاستظهار وسلبياته، من الناحية المعرفية والعلمية، ونبني بذلك إنسان الاستخلاف الذي يتمتع بالقدرة والعزة والكرامه.

إنّ عيوب تكوينا النفسي والوجداني، وقصورنا العلمي والمعريف، وعجزنا العمراني والحضاري مرده إلى تشويه رؤيتنا الكونية وقصور منهجنا الفكري اللذين أسهما وتكاتفا في انططاط منهجنا التربوي والتعليمي وقصور أدائنا واغهيار مؤسسات بجتمعاتنا. 
لذلك لابد للمفكرين والتربويين من العمل السريع الجاد على التخلص من: - الرؤية العقيدية الكونية الاجتماعية السلبية المشوهة. - والمنهج الفكري الجزئي القاصر.

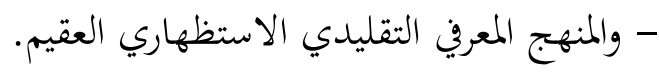
- والمنهج التربوي الإرهابي المدمر.

إنّ مسؤولية التنقية الثقافية والإصلاح التربوي هي مسؤولية المفكرين والعلماء والمثقفين الإسلاميين، الذين يقع عليهم واجب التمعن وإعادة النظر في موروثنا الفكري الثقافي الذي تمتد فيه جذور تكويننا الاجتماعي والنفسي والوجداني، وأن يقوموا بتنقيته وإعادة صياغته وعرضه مبرءاً من التشوهات والانحرافات بأسلوب يوحد منطلقات ثقافة الأمة وفكرها ووجداها وضميرها، ويتواصل مع مواقعها وامكاناتا وحاجاتا وتحدياتما. إنّ على المفكرين والعلماء والمثقفين المسلمين أن يقصدوا منهجياً بالخطاب والاقناع صاحب المصلحة المدفوع فطرياً إلى السعي إلى حسن تربية الناشئة والحرص عليها دون سواها، إنّ حس الأبوة الغريزي يقصد فطرياً إلى مصلحة الناشيء وحده ودون غاية أخرى، هذا يمثل المحرك الأساسي الدافع إلى التغيير لمصلحة الناشئة ومستقبل الأمة. ودافع الإصلاح التربوي الفطري والاستثمار في العود الطفولي الطريّ، الذي يستقيم به العود ويسري به في شرايين الناشئة زاكي الوجدان، ويضيیء في تلافيف العقل نور العلم والعرفان، فتعطي الناشئة والشبيبة والرجولة ثمراً خيراً نافعاً صلب العود، طيب النكهة، حلو المذاق.

إنّ الطفولة والمراهقة هما المرحلتان اللتان يتم فيهما إرساء قواعد البناء النفسي والوجداني الذي لخيار الرجال وفضليات النساء في مستقبل الأمة، ويبلور طبيعة الفرد الفكرية والاجتماعية، فالناس معادن، وخياركم في الجاهلية خياركم في الإسلام، ولآَباء في هذه المرحلة بالدرجة الأولى الأثر الأكبر في تشكيل نفسية الناشئة وطبيعة انفعالاهما الوجدانية، فالوالدان هما بمنزلة العدسات الملونة على أعين الأبناء، فليس المهم معها ما يرى الناشئ أو يسمع، ولكن المهم كيف يفهم ما يرى ويدرك ما يسمع، لأنّ تأثير الآباء وتوجيهاقم وأساليبهم في 
التواصل مع هؤلاء الأطفال واليافعين ومساعدقم في اختيار أصدقائهم وجلسائهم له أكبر الأثر في تشكيل وجدافم ونفسياقم وبالكيفية وبالقدر الذي تطيقه طاقات الناشئ وقدراته العقلية والنفسية والجسمانية.

إنّ توفير الثقافة التربوية السليمة للآباء وتزويدهم بالخبرات اللازمة -من خلال الأدبيات التي ينتجها المفكرون والتربويون المسلمون كيفاً وكماً- سيكون له أكبر الأثر في توجهات الناشئة وتكوين عقلياتم، لتربية جيل جديد قادر معرفياً ونفسياً وعقيدياً، ليصبح مؤهلاً وقادراً على إحداث الإصلاح والتقدم الاجتماعي المطلوب. إنّ ما يقع فيه الآباء من التقصير راجع في الغالب إلى جهلهم بالمطلوب منهم وما يحقق مصلحة

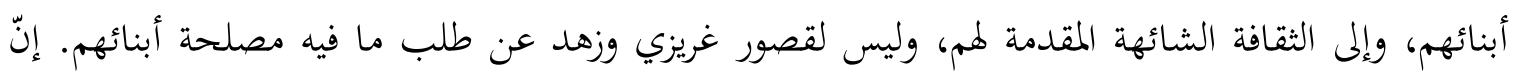
واجب المفكرين والتربويين أن يقدموا القدر الكافي الميسر من الأدبيات العلمية التربوية التي تبصر الآباء وتكسب قناعتهم، وأن يوفروا لهم سيولاً دافقة شيقة متعة من المفاهيم والمعلومات العلمية السهلة الميسرة التي يككنهم من أداء مهمتهم وتوجيه أبنائهم.

ويأتي بعد ذلك وبشكل موازٍ ما يوجه من أدبيات تعليمية وتربوية إلى المعلمين تبصرهم بالآفات والتشوهات الثقافية والتربوية وبدائلها الإيجابية، وتزودهم بالأفكار والمناهج والوسائل التي تساند جهودهم التربوية والتعليمية ضمن إطارهم الوظيفي لما يتميز به المعلم المخلص من حب الخير لتلاميذه وطلابه.

أما السياسات الحكومية والإعلامية فالتغييرات الأساسية فيها أصعب وأطول مدى وهي تحدث عادة تبعاً للوعي الذي تدفعه التغيرات التي تحدث في عقلية جمهور الأمة ووجداها وتؤثر تلقائياً في طبيعة توجهاتما ومصالحها، ولذلك يجب على المفكرين والتربويين عدم تعجل نتائج خطاب المؤسسات والسياسات العامة والسعي لترشيدها. إنّ جوهر عبء التغيير الفكري والاجتماعي والحضاري يقع على عاتق المفكرين والعلماء والتربويين من خلال دوافع الآباء وعواطف المعلمين بالدرجة الأولى، وعليهم المبادرة بحمل مسئولياتم دون انتظار للأدوار الرسمية التي تأتي ثمرة واستجابة لجهودهم و تأثيرهم في قاعدة بناء فكر ناشئة الأمة وبنائهم النفسي وتوجهاقم الوجدانية.

إنّ الطفل وتنميته الفكرية والنفسية، كانت وما تزال تتثل البعد الغائب في أداء مفكري الأمة ودعاة الإصلاح فيها، وكان خطاهم -وما يزال- يُعْنَ بالبالغين ويوجه إليهم، ولابد لإحداث تغيير جذري في 
وجدان الأمة وبنائها النفسي وتكوينها الفكري أن يبادر المفكرون والعلماء والمثقفون والقادة إلى سد هذه الثغرة واستعادة الأسس الثقافية والتربوية حتى نستعيد هذا البعد ونبني القدرة والطاقة اللازمتين لنجاح مشروع الإصلاح الإسلامي في النفس والمجتمع.

خاتمة:

تضمنت هذه الورقة إشارات موجزة إلى معالم الرؤية الكونية الإسلامية التي أرسى القرآن الكريم أسسها، وتكون على إساسها جيل الصحابة عليهم الرضوان، الذين رباهم النبي صلى الله عليه وسلم وتعهدةم عناية الوحي بالتصويب والترشيد. وقد اتصفت هذه الرؤية بالبعد الكلي الشمولي، والحس العام الاجتماعي الإنساني، والتوجه الإيجابي العمراني. وقد صاحب التاريخ الإسلامي منذ وقت مبكر سلسلة من العوامل التي حدّت من فاعلية هذه الرؤية الكونية وعوّقت من قدرقا على استمرار بناء الأجيال المسلمة القادرة على حمل أمانة الرسالة على الصورة التي أدّاها جيل الصحابة، وما لبثت هذه العوامل أن تعمق أثرها حتى فقدت الأمة حيويتها وعطاءها وقدرتها على توجيه الحضارة الإنسانية والريادة البشرية.

وأشارت الورقة إلى أن سبيل الإصلاح يقتضي إعادة النظر في الرؤية الكونية السائدة لتسقي مرجعيتها من القرآن الكريم وتنقى من التشوهات التي شابتها في مراحل التخلف والضعف، ومن تَّه إعمال الرؤية القرآنية لتصحيح مناهج الفكر عند الأمة لإعادة التوازن بين النص الصحيح والعقل الصريح، وبناء منهج تربوي يرفع عن أبناء الأمة سلطة القهر والترهيب لتنطلق طاقاقم الخيرة وقدراتم المبدعة في العطاء والبناء الحضاري.

وقد مارس الكاتب في تعامله مع القضايا المطروحة قدراً من النظر التحليلي النقدي، الذي يشخص الأبعاد الإيجابية والطاقات الكامنة في تراث الأمة وتاريخها، ويشير في الوقت نفسه إلى السلبيات وجوانب القصور التي تحتاج إلى استدراك ومعالجة، ودعا مفكري الأمة إلى تحمل مسؤولياتم في استكمال متطلبات الوعي بالتاريخ والواقع وطموحات المستقبل لتكمين الأمة من استعادة موقعها الريادي وفوضها الحضاري. 
ولم يكن القصد من هذه النظرة الناقدة إلقاء اللوم على أحد أو جيل، أو قويناً من شأن عطاء الأجيال السالفة على أزماها، وما حققته بما هلت به من روح الإسلام من إنجازات جعلت الأمة لأمد طويل وبكل المقاييس هي منارة العلم والحضارة الإنسانية. كما أنه ليس من أهداف هذا البحث التقليل من شأن أي جهد لأي فئة من فئات الأمة تقوم على أي ثغرة من ثغرات جهادها في السياسة والاقتصاد والتعليم والدعوة والذود عن الحياض، فكل ذلك واجب والبقاء على ثغراته ضرورة، وكل ما يقصد إليه هذا البحث والعرض هو مزيد من ترشيد العمل ودعم قواعده وتفعيل طاقاته، وإعداد الأجيال عقيدياً ومعرفياً ونفسياً بشكل أفضل وقدرة أكبر وأداء أكمل بواجبات جهاد الحياة الإسلامية وأمانة الاستخلاف على مختلف رست وجوها، لتمكين الأمة من تحقيق أهداف مشروعها الإصلاحي بإذن الله.

إنّ القصد من هذا المقال هو الاتصال مجدداً بروح الإسلام ودفعه الإيماني العمراني لمواجهة تحديات زماننا وبوسائلنا وإمكاناتنا، وبروح الإقدام والإبداع التي نحن أهلٌ لها، مستفيدين من إيجابيات تراث الأجيال التي أسهمت في خدمة الأمة والحضارة، ونتخطى عثراتم التي أملتها ظروفهم التاريخية، ونتواصل معهم في دفع الحياة بابتاه الحق والهدى وقصد الخير وعمارة الكون، وطرح التحدي الإسلامي ورؤيته التوحيدية الأخلاقية الاستخلافية في عمارة الكون وهداية البشرية أمام الإنسانية وحضارتا بشكل وأسلوب جاد ناجح مقنع. والله من وراء القصد ومنه سبحانه العون والتوفيق. 